Original Article for submission to Journal of Cleaner Production

\title{
Designing consumer electronic products for the circular economy using recycled Acrylonitrile Butadiene Styrene (ABS): a case study
}

\author{
Peter Ford ${ }^{\mathrm{a}, 1}$ peter.ford@ntu.ac.uk (corresponding author) \\ Jill Fisher j.jfisher@dmu.ac.uk \\ a The Design Unit, De Montfort University, Vijay Patel POD 3.13, The Gateway, Leicester, LE1 9BH \\ ${ }^{1}$ Present Address: Design Matter, School of Art \& Design, Nottingham Trent University, 50 \\ Shakespeare Street, Nottingham NG1 4FQ
}

Declarations of interest: none.

Acknowledgements: Funding: this research was fully funded by British Telecom who had no role in in the collection, analysis or interpretation of data; in the writing of the report, or in the decision to submit the article for publication.

\begin{abstract}
This study considers the feasibility of using $100 \%$ recycled Acrylonitrile Butadiene Styrene (rABS) in the caseworks of small consumer electronic products as a step towards more circular design and manufacturing. A Digitally Enhanced Cordless Telephone (DECT) handset was chosen as a representative example of such a product. Materials testing on the rABS demonstrated that $100 \%$ recycled $A B S$ has similar properties to virgin $A B S$ and can be substituted for virgin $A B S$ as long as the product design allows for the slightly stiffer nature of the $\mathrm{rABS}$ and addresses issues of surface finish and ability to colour. By clearly understanding these issues at the outset of the design process, and by adapting the designs appropriately at the outset, it was possible to produce an rABS handset which was as robust and as cosmetically acceptable as one made of virgin ABS. This suggests that the recycled material could be used widely in this type of product and also at reduced cost to using virgin ABS. Furthermore, an abridged Life Cycle Analysis of the existing handset suggested that other issues associated with the environmental impact of the product could be relatively easily addressed at the design stage by considering energy use and end of life issues
\end{abstract}

\section{Keywords}

Recycled ABS; circular economy; design for environment; end of life; electronic product; life-cycle assessment

\section{Introduction}

It is generally accepted that designers play a fundamental role in determining the environmental impact of a product in the early stages of the product design process (De los Rios and Charnley 2017, Maxwell and van der Vorst 2002, Ramani et al. 2010). It is the role of the designer to assimilate complex design issues including commercial, visual and technical aspects in these early stages in order to minimise potential compromise on the resulting product. Increasingly issues relating to the environment and sustainability are being added to this list of requirements (Rosen and Kishawy 2012).

For many years companies have adopted a linear model in the approach to the design, manufacture, use and disposal of products. Various pieces of legislation from the EU (and more recently other 
areas of the world) have led to the restriction of the use of certain materials and a legal requirement to collect and recycle certain types of products, most notably vehicles and electrical and electronic equipment. Although this has had some effect on product design practices, many manufacturers are still determining how to address the full life cycle impacts of products at the design stage (Bocken et al. 2016).

If companies are to move towards a truly circular approach to product manufacture, it requires a new way of undertaking product design. Indeed many authors are now stressing the importance of designing for multiple life cycles (eg. Go et al. 2015). This shift is not as complex or challenging as it may first appear. The main aims of a circular economy are well defined (EMF 2012) and the benefits they bring are clear from both an environmental and cost perspective. To move away from the current take - make - use - dispose model, products need to be designed with recycling and reuse in mind and designers need to work with recycled and reclaimed materials. This requires more than attempting to directly replace virgin materials with recycled materials in existing product designs. The properties of the recycled materials must be taken into account in the earliest stages of the design process to ensure design integrity from the outset. Furthermore, products must be easy to disassemble to allow for refurbishment and material reclamation.

A large UK based producer and retailer of telecommunication products (TP) commissioned the authors to explore the potential use of recycled ABS in its products to help it fulfil its commitment to circular economy principals. The overall goal was to produce products which met customer expectations while minimising the environmental impacts inherent in their manufacture and use with the aim of moving towards fully circular manufacturing.

TP produces a range of telecommunication products, primarily for the UK market, thousands of which are manufactured and distributed yearly. To meet this demand TP contracts a number of Pacific Rim and China based manufacturers to develop and manufacture products to TP's specification. Although the individual impact of these products is small, overall this activity represents a significant tonnage of product being distributed, and ultimately disposed of, within the UK. These products fit into the category of medium-lived consumer products which has been identified as a "sweet-spot segment for circularity" (EMF 2013, p. 36).

A significant proportion of TP's product range is made up of devices consisting of electronic assemblies clad in an external, plastic, injection moulded casework. The polymer normally specified for these products is Acrylonitrile Butadiene Styrene (ABS), as it has the best balance of the required cosmetic, mechanical and economic qualities; it is also recyclable. TP had become aware of a grade of $100 \%$ recycled $A B S$ ( $r A B S$ ), produced from a controlled source of recyclate material that was becoming commercially available. The rABS (ABS 4124) was produced by MBA polymers in Germany. The key was ensuring a known, consistent source of recyclate.

After internal components and assemblies, product casework parts generally constitute the majority of product content for small electrical products. Therefore, TP was interested in exploring the possibility of substituting rABS for the virgin ABS currently being used in its products. The use of $100 \%$ recycled material in product casework would represent a significant reduction in the end of life impact of the products and would be a move toward a more 'circular' design.

The goal of this project was therefore to provide evidence-based recommendations to TP on a number of key issues in the design of their products focussing on using $100 \%$ recycled $A B S$ with regard to its cosmetic, construction and mechanical performance. For this exercise an existing TP Digitally Enhanced Cordless Telephone (DECT) was chosen as a representative example. 
Use of $100 \%$ recycled plastics in electrical and electronic equipment is still in its infancy with the use of $10 \%$ of recycled $A B S$ in a mixed resin considered worthy of a closed loop certification (Vlugter 2017). Although there has been some research on the properties of post-consumer/virgin ABS blends (eg. Scaffaro et al 2012, Souza and Cucchiara 2018) surprisingly few data were available on the properties and use of $100 \%$ rABS. Therefore, materials testing to compare the properties of the rABS against virgin $A B S$ was undertaken to explore the characteristics of this new material, its limits and what might be done to mitigate against them through design. The project consisted of two phases. In the first phase, materials testing and initial design scoping were carried out to compare the properties of virgin and recycled plastic. Although the initial focus of the work was to assess the suitability of $\mathrm{rABS}$ as a replacement for virgin ABS a Life Cycle Assessment (LCA) was also conducted to explore the overall environmental impact of the existing DECT phone (including the handset, base, and packaging) and to identify additional areas for potential improvement. This also allowed for comparison between the existing phone and a more circular design. LCA is accepted as important in new product design, but it is also of growing importance in assessing existing products and in guiding redesign (Bakker et al. 2014). Chang et al (2014) point out that product design and development has been neglected in LCA research and stress the usefulness of LCA in sustainable product design, and Yung et al (2011) demonstrate the usefulness of LCA in assessing and redesigning personal electronic products.

As a follow on from the initial exploration of the use of rABS and the LCA of the existing phone, TP became interested in exploring other approaches to reducing the environmental impact of the product. The second phase therefore explored design alternatives to facilitate the use of recycled materials and to minimise other environmental impacts of the phone. To begin to meet the needs of the circular economy the design needed to both utilise recycled and/or reclaimed components and to be easy to disassemble to provide recyclable materials and reusable components for future lives.

Using data from the materials testing and the LCA various design options were explored. Two distinct prototypes were produced, the first of which was rejected by TP on the basis of likely market reaction. TP's reaction to the second prototype was more positive, and injection moulded samples were produced and subjected to a variety of mechanical tests to ensure that the new design was robust. In addition, a further LCA was conducted to allow comparison with the original design.

\section{Phase 1 - Method}

\subsection{Materials analysis}

The first step was to undertake a direct comparative analysis between non-recycled (virgin) ABS and $100 \%$ recycled $A B S(\mathrm{r} A B S$ ) to assess whether $\mathrm{ABS}$ could be used as a direct replacement for virgin $A B S$ in the manufacture of the DECT handset and, if not, to determine where design adaptations might be needed. There were three areas of concern in substituting $100 \%$ rABS for the virgin ABS used in the original design of the DECT handset: strength, surface finish, and ability to colour. Materials under specific consideration were a virgin ABS - Tairilac AG 15A1 (by Formosa Chemicals) and $4124100 \%$ rABS from MBA Polymers. Test parts for finish and for stress testing were not available for these materials so an injection moulding tool was commissioned to produce test strips to undertake stress/elongation testing (on industry standard test equipment) and test plaques to observe differences in surface finish (from gloss to coarse texture) and colour. 


\subsubsection{Strength}

Injection moulded test strips were produced to compare tensile strength performance of both virgin and rABS materials. Tensile tests were conducted on the moulded material sample strips using an Instron 3367 Dual Column Testing System. Using the data obtained from the stress/strain to elongation measurements, Finite Element Analysis (FEA) was undertaken to evaluate the stress on the clip design (to hold body halves together) of the DECT handset for both the virgin ABS and the rABS.

\subsubsection{Surface finish}

Criteria being investigated were finish (surface texture), and ability to colour (paint, print, etc.). Injection moulded test plaques were produced to determine ability to colour (using master batch pigment) and paint. These test plaques were also spark eroded at four different levels to explore alternative surface textures. Test plaques were assessed visually.

\subsection{Life Cycle Assessment}

The overall environmental impact of the DECT phone was assessed using an abridged LCA analysis. LCA is a technique used to assess environmental impacts associated with all the stages of a product's life from-cradle-to-grave. A full LCA requires the collection of specific data related to the exact materials and manufacturing practices used and the results of such studies are usually complex and difficult for non-experts to understand. An abridged LCA uses the same principles as full LCA in that it considers the whole life cycle of a product but it uses secondary data (from published datasets) and considers a more limited number of impacts such as carbon and energy footprints (Cooper 2005).

The assessment of the DECT phone was carried out using an abridged LCA technique through the use of the Eco Audit function of the Cambridge Engineering Selector (CES) software (Granta 2018). This assessment requires the input of a bill of materials for the product in question and the definition of generic processing routes as well as information relating to energy consumption during use and likely disposal routes at end of life. Data for the Life Cycle Analysis were partially provided by the manufacturer, with further information provided by disassembling the existing model.

\subsection{Physical Teardown and Assessment}

Detailed bills of materials containing a list of materials, components and weights were not available for the DECT phone and therefore the product was physically disassembled to allow the identification of material types, the measurement of their weights and the assessment of processing routes used. Where components or materials were joined together, they were separated if possible. Where multi-material components were impossible to separate estimates were made in regard of the weights of the different constituent materials. As well as assessing quantifiable parameters the product was considered in respect of use of recycled content, ease of recyclability and design features that affect Circular Economy principles.

\subsection{Use of CES Software}

The quantitative information gained from the physical teardown stage was used to undertake a whole-life impact assessment using Cambridge Engineering Selector (CES) software (Granta 2018). 
This software uses a database of materials properties (which included environmental measures such as Energy and $\mathrm{CO}$ e) to generate a whole life cycle impact and communicate how each life cycle stage contributes to this.

The bill of materials was entered and estimates of energy consumption during use were also added. The phone is manufactured in China so the transport of the products to the UK by sea freight was included in the assessment. Finally, the expected end of life scenario for the product was described in CES. As this product is a small electrical item which comes under the requirements of the WEEE Directive it is anticipated that it would be returned or collected for recovery and recycling. In the majority of cases these types of products are shredded and material recovery is undertaken where possible. For the assessment an end of life scenario of 'downcycling' was specified for the majority of materials as it is very unlikely that they would go through a closed loop recycling process and the materials be re-used in similar products. The expected life of the product was set at 5 years.

\section{Phase 1 Results}

\subsection{Materials analysis}

\subsubsection{Strength}

The results show that although the $\mathrm{ABS}$ and virgin $A B S$ have similar yield points, $\mathrm{r} A B S$ has a much more immediate failure point (Figures 1 and 2). In addition, when subject to loads beyond its yield point, $\% 100$ rABS will fail far more abruptly than virgin ABS. As the two materials have similar yield points these results suggest that $\mathrm{rABS}$ could be substituted for virgin ABS in the handset assuming that it is possible to design the handset to withstand higher impact, or to utilise an assembly method that would compensate for this failure characteristic.

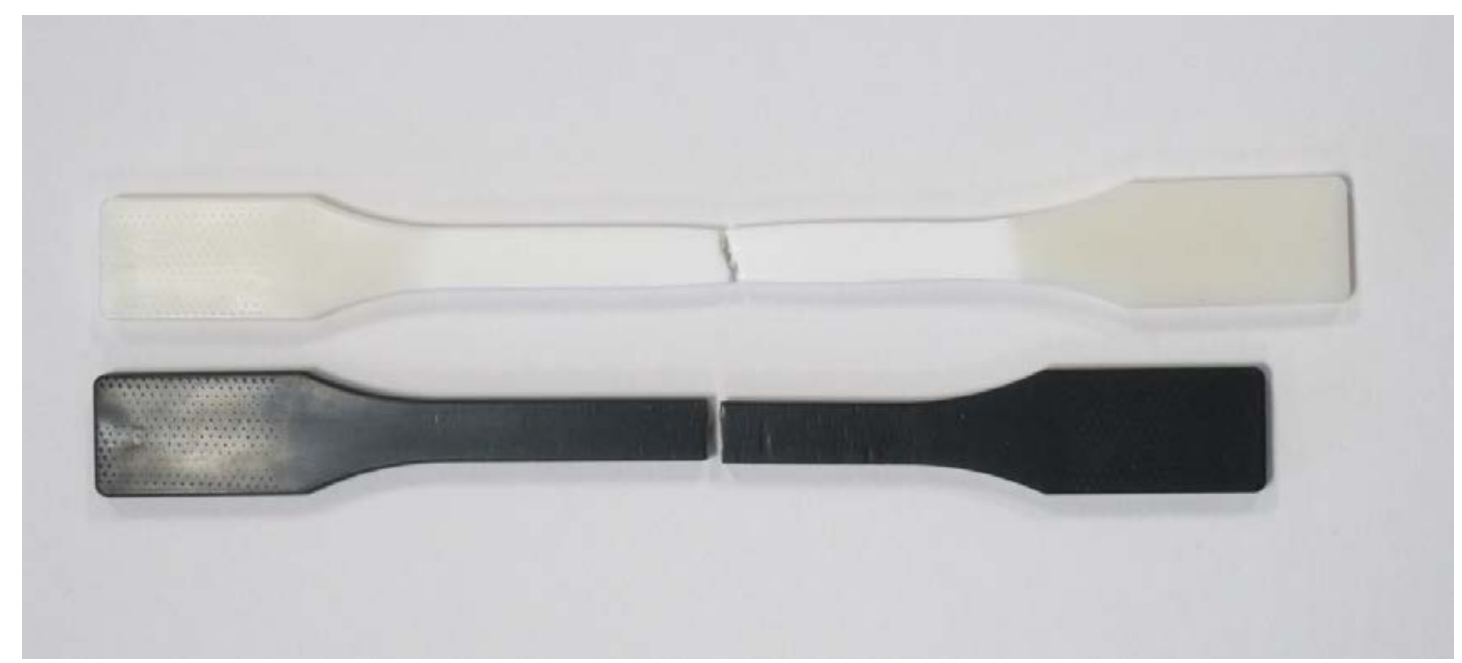

Figure 1 Elongation to break evaluation-virgin ABS at top, 100\% rABS below 


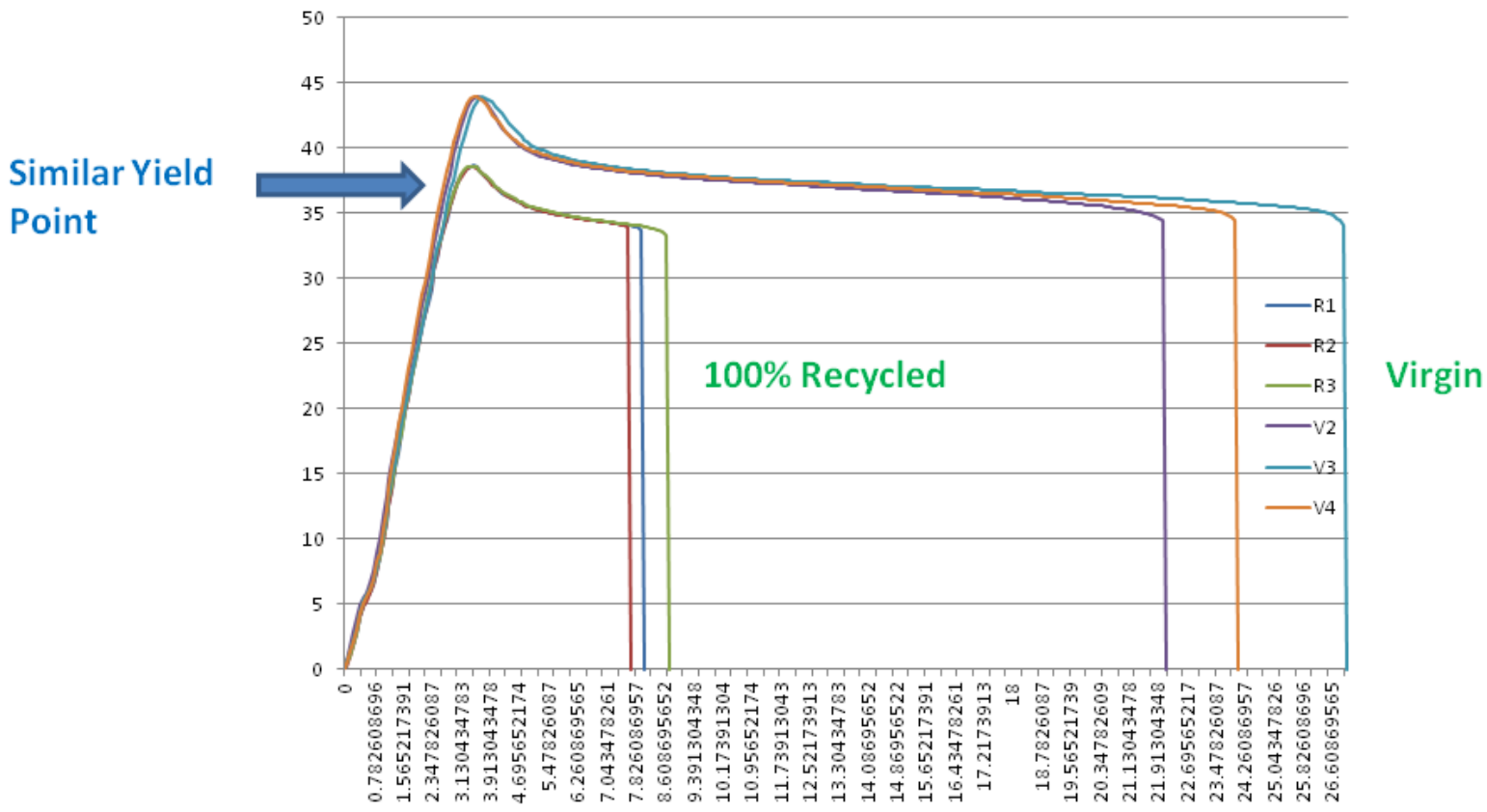

Figure 2 Failure points of virgin and rABS using three samples of each

\subsubsection{Finite element analysis}

Using the data obtained from the stress/strain to elongation measurements, FEA was undertaken to evaluate the stress on the clip design (to hold body halves together) of the DECT handset. This indicated a stress concentration at the root of the clip half (Figure 3). However this element does not occur right the way through the feature. Although not ideal, this was not considered to be a major cause for concern.

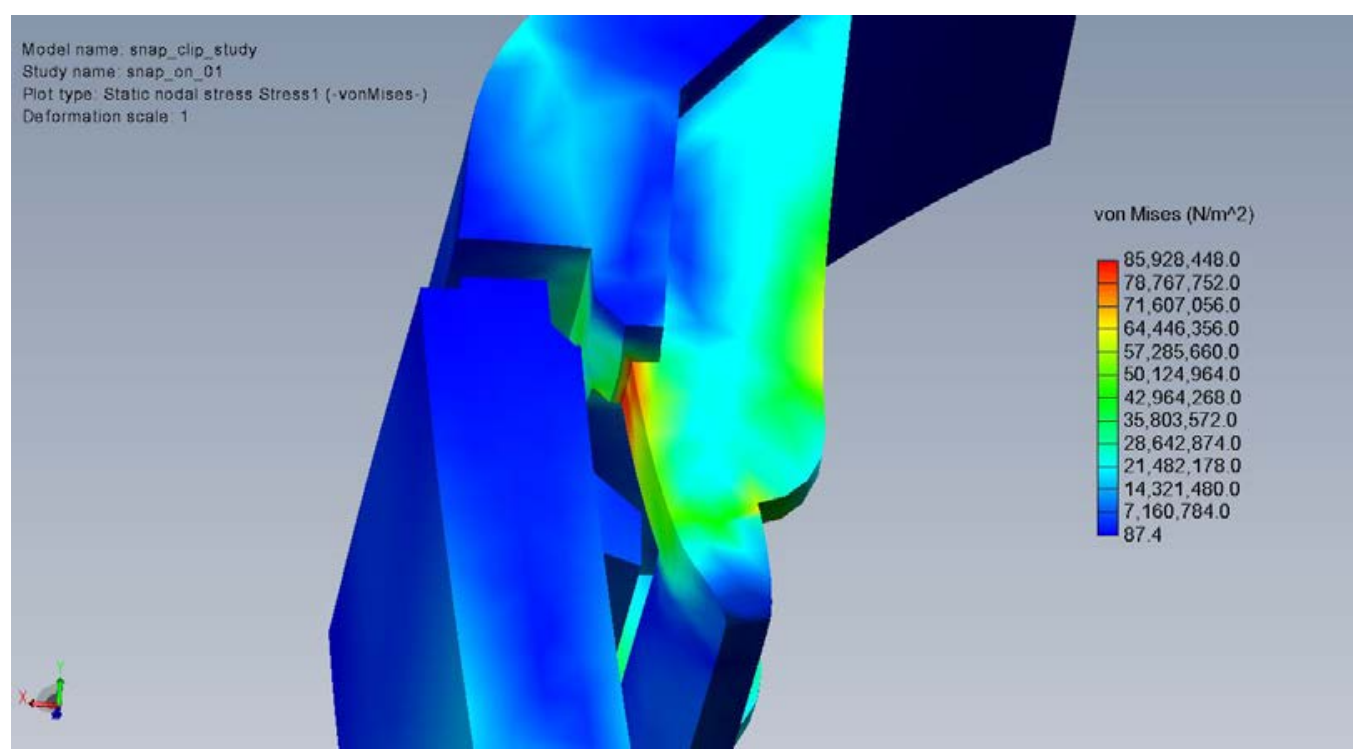

Figure 3 Stress/strain in DECT handset clip

In terms of design, due to the stiffer nature of the $100 \%$ rABS, it would be prudent to avoid clip features subject to significant stress, or at least to use design features (predominantly root radii) that minimise/avoid stress raisers. 
Further FEA also indicated that simply making the clips stronger by increasing their thickness would actually be counterproductive, as it would increase stiffness and contribute to failure. Making the clips longer, such that they could flex more easily would resolve the problem, but this would also make it easier for the body halves to separate when subject to a standard drop test. This suggests that a complete redesign of the method of holding the two body halves together would be necessary if $r A B S$ was to be used instead of virgin ABS.

\subsubsection{Surface finish}

The test plaques for surface finish (with 3\% black 'master batch' colouring added) demonstrated that a glossy surface finish would reveal evidence of small contaminants (inclusions) in the $100 \%$ rABS which were clearly visible with the naked eye. Applying a texture to the surface, however, effectively masked these inclusions.

\subsubsection{Colour}

The results of adding white batch colouring to the $100 \%$ rABS compared to adding white batch colouring to virgin $A B S$ can be seen in Figure 5. Attempts to produce primary colours yielded similar 'dirty' results. Black or shades of dark to mid grey are the only possibilities Therefore it would appear that $100 \%$ rABS is problematic to colour using the industry standard master batch colouring process (Figure 4).

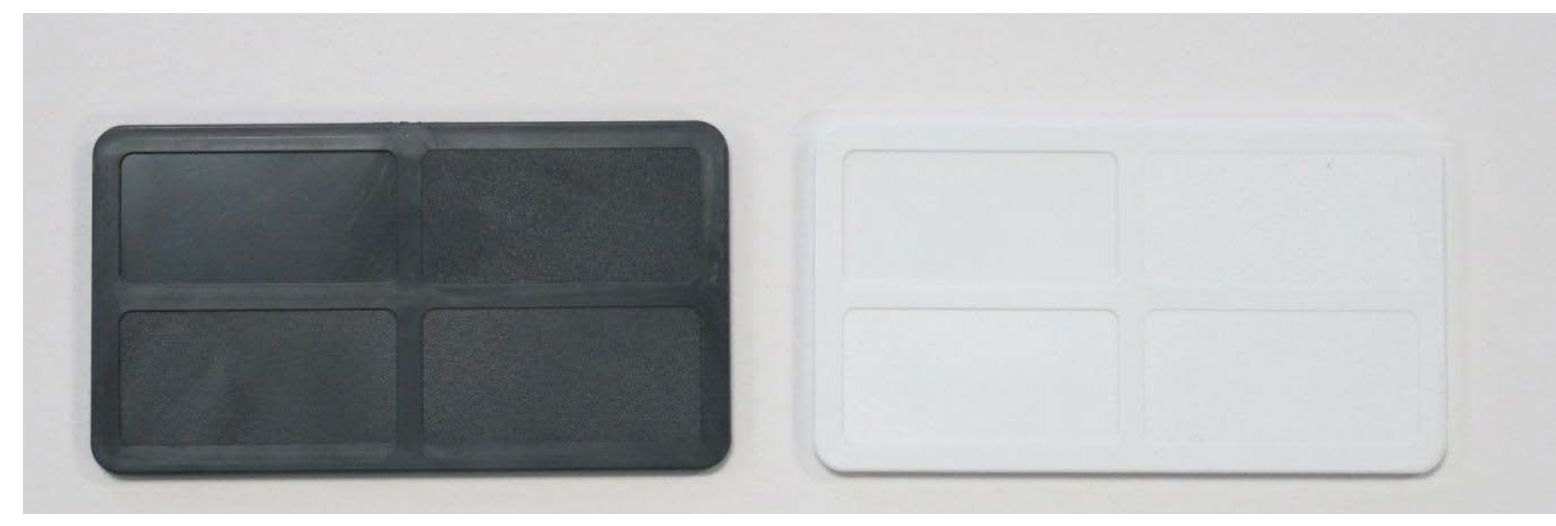

Figure 4 Attempts to colour $r A B S$ compared to virgin $A B S-r A B S$ is on the left and virgin $A B S$ is on the right

The rABS accepts paint as well as virgin material but this introduces a further set of issues as the paint would contaminate the $\mathrm{rABS}$ for further processing and contribute to environmental impact of the handset.

\subsection{Life Cycle Analysis}

A summary of the overall life cycle impacts of the existing DECT phone in terms of energy use is shown in Figure 5 and Table 2 contains a full materials list. 


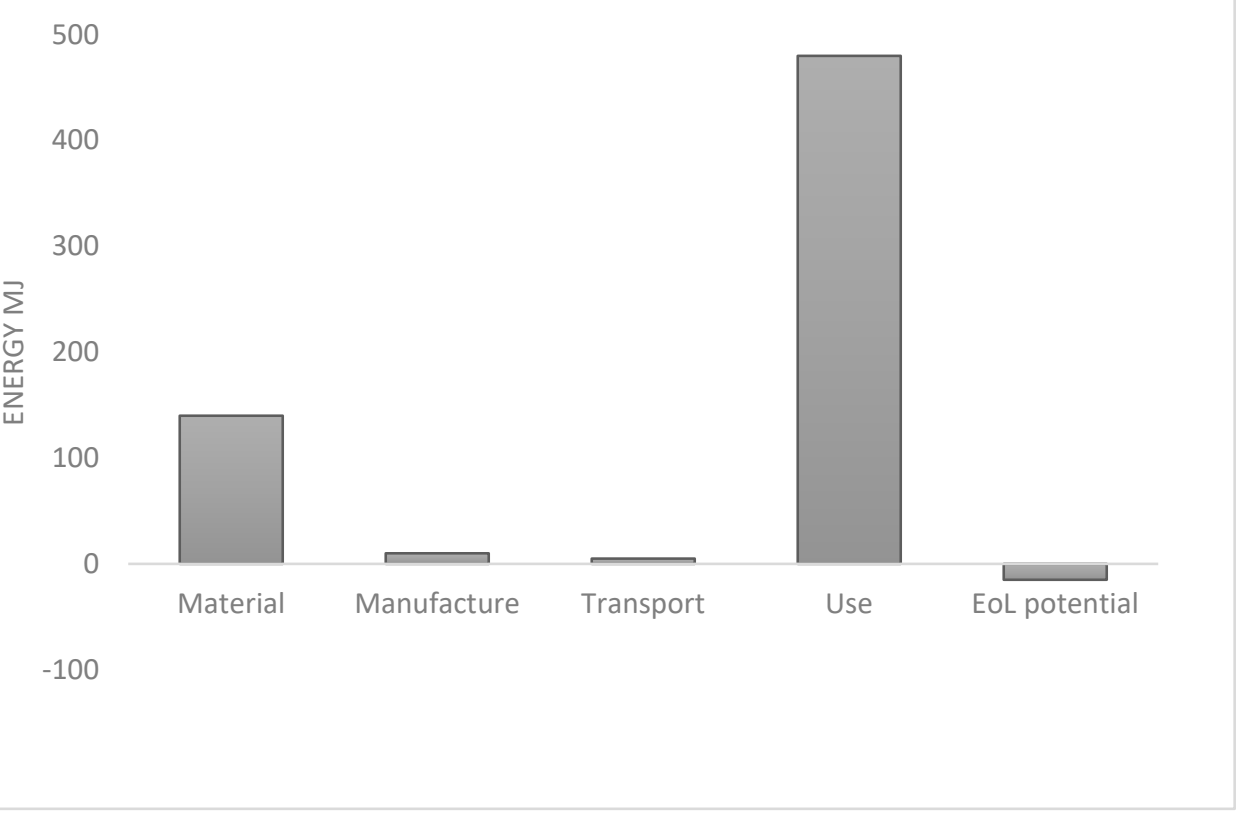

Figure 5 Life cycle energy impact of DECT handset assuming a 5-year life

Table 1 Materials list for Existing DECT phone including packaging

\begin{tabular}{|c|c|c|c|c|c|c|c|}
\hline Component & Material & $\begin{array}{c}\text { Recycled } \\
\text { content* }^{*}(\%)\end{array}$ & \begin{tabular}{|c|} 
Part \\
mass \\
$(\mathbf{k g})$ \\
\end{tabular} & Qty. & $\begin{array}{c}\text { Total mass } \\
\text { processed }^{* \star} \\
(\mathrm{kg})\end{array}$ & $\begin{array}{l}\text { Energy } \\
\text { (MJ) }\end{array}$ & $\%$ \\
\hline Packaging (outer box) & Cardboard & $50.0 \%$ & 0.084 & 1 & 0.088 & 2.8 & 2.0 \\
\hline Packaging inner box & Paper (cellulose based) & $75.0 \%$ & 0.14 & 1 & 0.15 & 4.4 & 3.2 \\
\hline Handset upper casing & $\begin{array}{l}\text { ABS (medium-impact, } \\
\text { injection molding) }\end{array}$ & Virgin $(0 \%)$ & 0.021 & 2 & 0.042 & 4 & 2.9 \\
\hline Hanndset lower casing & $\begin{array}{l}\text { ABS (medium-impact, } \\
\text { injection molding) }\end{array}$ & Virgin $(0 \%)$ & 0.022 & 2 & 0.044 & 4.2 & 3.1 \\
\hline Handset battery cover & $\begin{array}{l}\text { ABS (medium-impact, } \\
\text { injection molding) }\end{array}$ & Virgin (0\%) & 0.087 & 2 & 0.17 & 17 & 12.1 \\
\hline Handset PCB & Printed circuit board assembly & Virgin (0\%) & 0.018 & 2 & 0.035 & 4.6 & 3.4 \\
\hline Handset LCD & $\begin{array}{l}\text { LCD panel (liquid crystal } \\
\text { display) }\end{array}$ & Virgin (0\%) & 0.0069 & 2 & 0.014 & 3.3 & 2.4 \\
\hline Handset LCD Diffuser & $\begin{array}{l}\text { PC (high viscosity, molding } \\
\text { and extrusion) }\end{array}$ & Virgin (0\%) & 0.0028 & 2 & 0.0056 & 0.61 & 0.4 \\
\hline Hanset LCD 'frame' & $\begin{array}{l}\text { ABS (medium-impact, } \\
\text { injection molding) }\end{array}$ & Virgin (0\%) & 0.0023 & 2 & 0.0046 & 0.44 & 0.3 \\
\hline Handset Speaker & $\begin{array}{c}\text { Carbon steel, AISI 1010, } \\
\text { annealed }\end{array}$ & Typical \% & 0.0035 & 2 & 0.007 & 0.13 & 0.1 \\
\hline Main base lower casing & $\begin{array}{l}\text { ABS (medium-impact, } \\
\text { injection molding) }\end{array}$ & Virgin (0\%) & 0.048 & 1 & 0.048 & 4.6 & 3.3 \\
\hline Main base upper casing & $\begin{array}{l}\text { ABS (medium-impact, } \\
\text { injection molding) }\end{array}$ & Virgin $(0 \%)$ & 0.028 & 1 & 0.028 & 2.7 & 1.9 \\
\hline Main base phone 'cradle' & $\begin{array}{l}\text { ABS (medium-impact, } \\
\text { injection molding) }\end{array}$ & Virgin (0\%) & 0.0048 & 1 & 0.0048 & 0.46 & 0.3 \\
\hline Main base upper circuit board & Printed circuit board assembly & Virgin (0\%) & 0.013 & 1 & 0.013 & 1.7 & 1.3 \\
\hline Main base lower circuit borad & Printed circuit board assembly & Virgin $(0 \%)$ & 0.0049 & 1 & 0.0049 & 0.64 & 0.5 \\
\hline Main base feet & $\begin{array}{l}\text { Ethylene propylene (diene) } \\
\text { (EPDM/EPM, unreinforced) }\end{array}$ & Virgin (0\%) & 0.0007 & 1 & 0.0007 & 0.066 & 0.0 \\
\hline Screws and metal contatcs & $\begin{array}{c}\text { Carbon steel, AISI 1010, } \\
\text { annealed }\end{array}$ & Typical \% & 0.0029 & 1 & 0.0029 & 0.053 & 0.0 \\
\hline Keypad frame & $\begin{array}{l}\text { ABS (medium-impact, } \\
\text { injection molding) }\end{array}$ & Virgin $(0 \%)$ & 0.0039 & 1 & 0.0039 & 0.37 & 0.3 \\
\hline
\end{tabular}




\begin{tabular}{|l|c|c|c|c|c|c|c|}
\hline Keypad buttons & $\begin{array}{c}\text { ABS (medium-impact, } \\
\text { injection molding) }\end{array}$ & Virgin (0\%) & 0.0049 & 1 & 0.0049 & 0.47 & 0.3 \\
\hline Keypad 'pad' & $\begin{array}{c}\text { Silicone (VMQ, heat cured, } \\
\text { low hardness) }\end{array}$ & Virgin (0\%) & 0.0064 & 1 & 0.0064 & 0.89 & 0.6 \\
\hline Slave base upper casing & $\begin{array}{c}\text { ABS (medium-impact, } \\
\text { injection molding) }\end{array}$ & Virgin (0\%) & 0.022 & 1 & 0.022 & 2.1 & 1.5 \\
\hline Slave base lower casing & $\begin{array}{c}\text { ABS (medium-impact, } \\
\text { injection molding) }\end{array}$ & Virgin (0\%) & 0.033 & 1 & 0.033 & 3.2 & 2.3 \\
\hline Slave base phone 'cradle' & $\begin{array}{c}\text { ABS (medium-impact, } \\
\text { injection molding) }\end{array}$ & Virgin (0\%) & 0.0048 & 1 & 0.0048 & 0.46 & 0.3 \\
\hline Slave base circuit board & Printed circuit board assembly & Virgin (0\%) & 0.0016 & 1 & 0.0016 & 0.21 & 0.2 \\
\hline Slave base wires & Cable & Virgin (0\%) & 0.0033 & 1 & 0.0033 & 0.3 & 0.2 \\
\hline $\begin{array}{l}\text { Slave base weight connectors } \\
\text { and screws }\end{array}$ & $\begin{array}{c}\text { Carbon steel, AISI 1010, } \\
\text { annealed }\end{array}$ & Typical \% & 0.033 & 1 & 0.033 & 0.6 & 0.4 \\
\hline Slave base feet & $\begin{array}{c}\text { Ethylene propylene (diene) } \\
\text { (EPDM/EPM, unreinforced) }\end{array}$ & Virgin (0\%) & 0.0007 & 1 & 0.0007 & 0.066 & 0.0 \\
\hline Power supply & Power supply unit & Virgin (0\%) & 0.085 & 2 & 0.17 & 77 & 56.3 \\
\hline Total & & & & $\mathbf{3 7}$ & $\mathbf{0 . 9 5}$ & $\mathbf{1 . 4 e + 0 2}$ & $\mathbf{1 0 0}$ \\
\hline
\end{tabular}

The overall recycled content of the current materials used (\% by weight) is low. The plastics contain no recycled content (as far as can be established) and the metals have been allocated the average recycled content that is in current supply chains. The majority of the recycled material content is in the cardboard of the packaging materials.

Only approximately $1 / 3$ of the weight of the materials used in these products can be easily recycled. This comes mainly from the materials used in the packaging and any metallic content of the products. A larger proportion could be 'downcycled' but this is not a key aim of the circular economy. It is much better to recover materials in a closed loop system and to be able to extract value from waste products.

From the assessment undertaken a set of issues related to material use and product design can be identified. The product uses a number of components which are manufactured from different materials. Some are bonded together and are not compatible for recycling. This means that the recovery of the materials at end of life becomes very difficult if not impossible. Practices observed included bonding foam to plastic components, bonding electronic components to plastic casings, bonding different types of plastics together, and coating screws with sealant. The key pads used in the products are particularly complex and it would be all but impossible to recover high grade materials for closed-loop recycling from them.

\section{Phase 2}

The initial materials analysis of the rABS identified two challenges in replacing virgin $A B S$ with $100 \%$ rABS in the DECT handset, clip design and surface finish, while the LCA identified several opportunities for reducing the environmental impact of the handset. These included using fewer components, avoiding the use of components made of multiple materials bonded together, and reducing the energy use of the handset. Given these results the second phase of the project was to explore design options to overcome these challenges and to reduce the overall environmental impact of the handset.

The two largest environmental impacts of the handset arise from energy use during its lifetime, and the materials used in manufacture. There are two routes to reducing the materials impact, one is to 
include more recycled materials in the handset and the other is to make the components reusable or recyclable.

\subsection{Possible Design Solutions}

Although the initial brief was to assess the strength, colour and texture of the rABS, a number of other possibilities for reducing the environmental impact of the handset arose in the course of this research. The first was that the existing mechanical keypad could be replaced with capacitive touch features on one side of the main PCB. The existing keypad was composed of 21 different components and 5 different materials including metals, elastomers and other polymers all of which were bonded together making for problematic end of life disassembly and disposal (Figure 6).
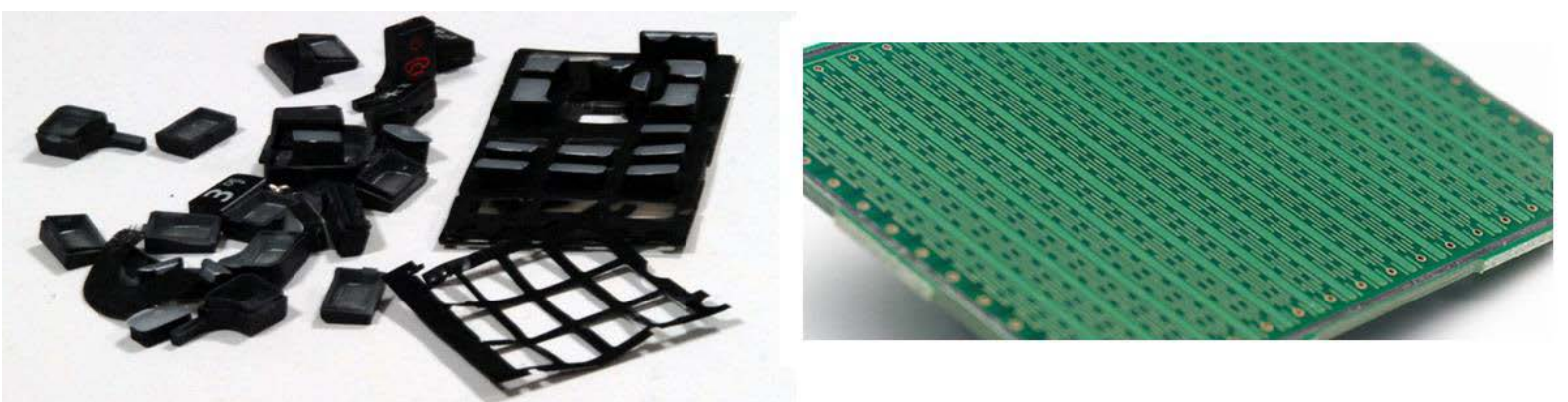

Figure 6 Existing multi-component keyboard (left) and proposed capacitive touch (right)

\subsubsection{First design concept}

Overcoming the issues with $\mathrm{rABS}$ required addressing three issues, clip strength, surface finish and colour. The first design solution explored using the existing handset design but substituted a capacitive keypad to reduce energy use and facilitate disassembly. To overcome the limitations of rABS a radical new approach to construction was proposed, using heat-shrink material (made possible by using the capacitive touch keypad) to provide colour and graphics, hold the two body halves together (no screws) and make it easy for end of life disassembly (just slit and remove the heat shrink material), Shrink-wrapping also could provide a way of extending product value as phones could be returned and re-wrapped (Figure 7).

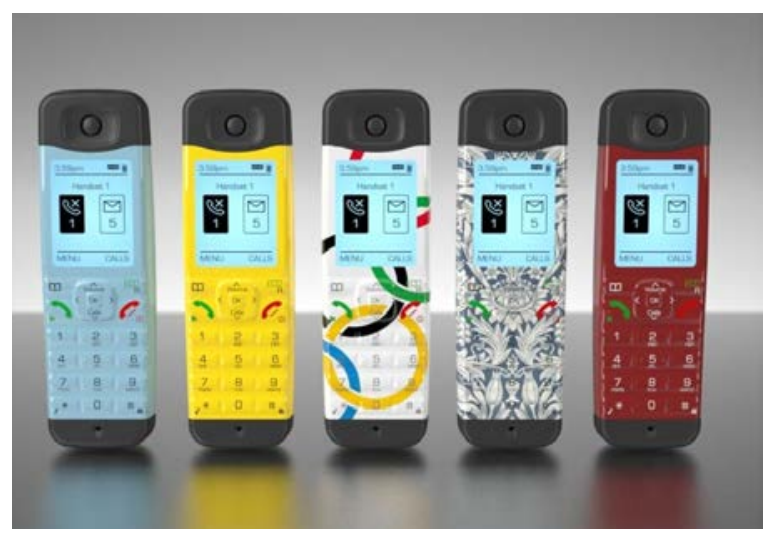

Figure 7 Using heat-shrink material to colour and hold together the DECT handset halves, original design concept 
An 'e-ink' display was also included in the design to reduce power consumption and therefore allow the number of rechargeable AAA batteries to be halved from two to one, thus reducing weight and material consumption and also lifetime energy use.

\subsubsection{First prototype}

The first design concept was presented to TP and they decided to commission prototypes to assess acceptability of the new design. TP's marketing team were concerned that this new approach and the lack of a mechanical keypad would not be acceptable to its customers (Figure 8). The feedback regarding the capacitive touch keypad and 'e-ink' display was positive but TP's marketing department then became concerned about the 'feel' of the shrink wrap which it did not think would be acceptable to customers.

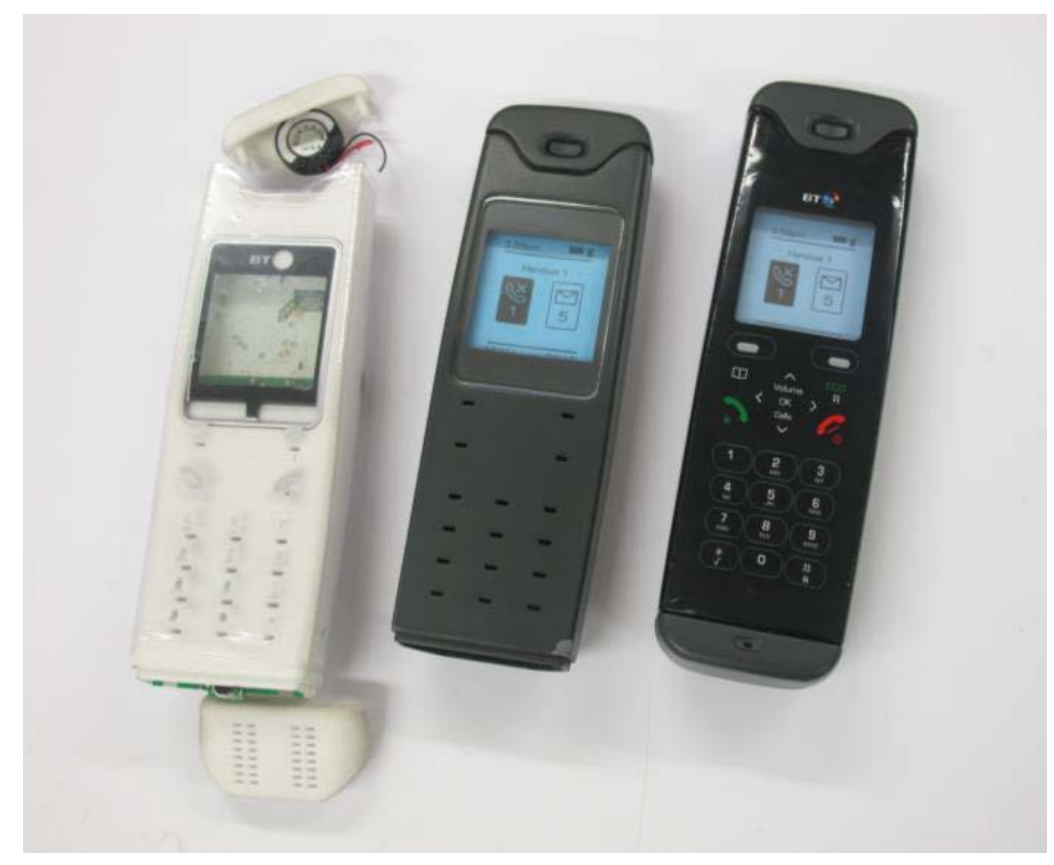

Figure 8 First prototype

\subsubsection{Second design concept}

Although TP identified potential marketing difficulties with the first edesign of the handset, they were interested in pursuing the concept of a handset that not only used rABS but also used a capacitive touch keypad and e-ink display. This led to the development of a completely new design of handset. The new design reverted to experimentation with surface texturing to provide a desirable visual effect and feel while creating a method of masking the imperfections in the rABS (Figure 9). This was combined with a paint finish to the front of the handset (Figure 10). However, a resolution of the clip issue was still necessary. 


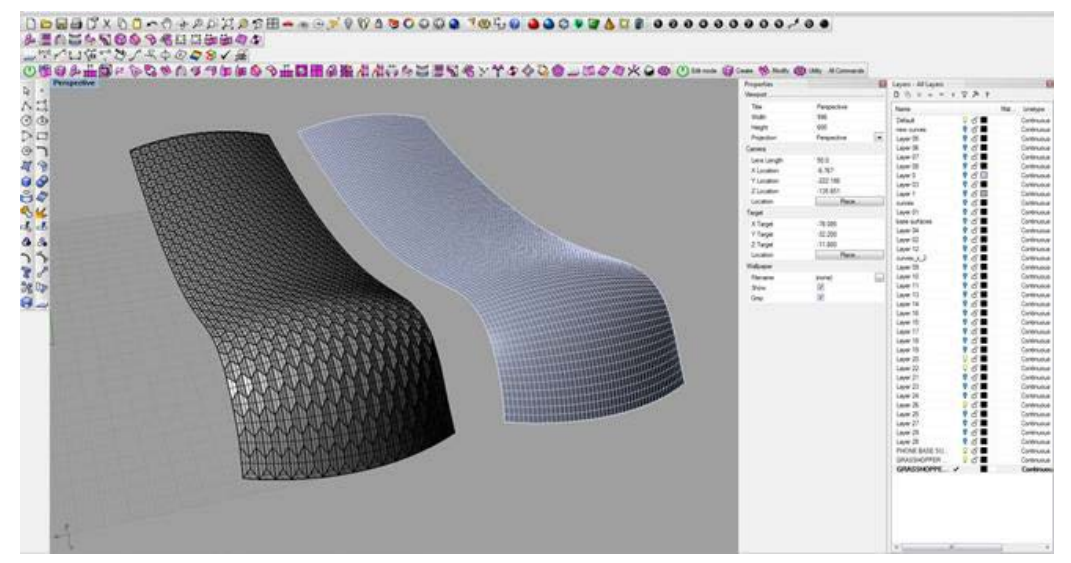

Figure 9 Experimenting with surface texturing

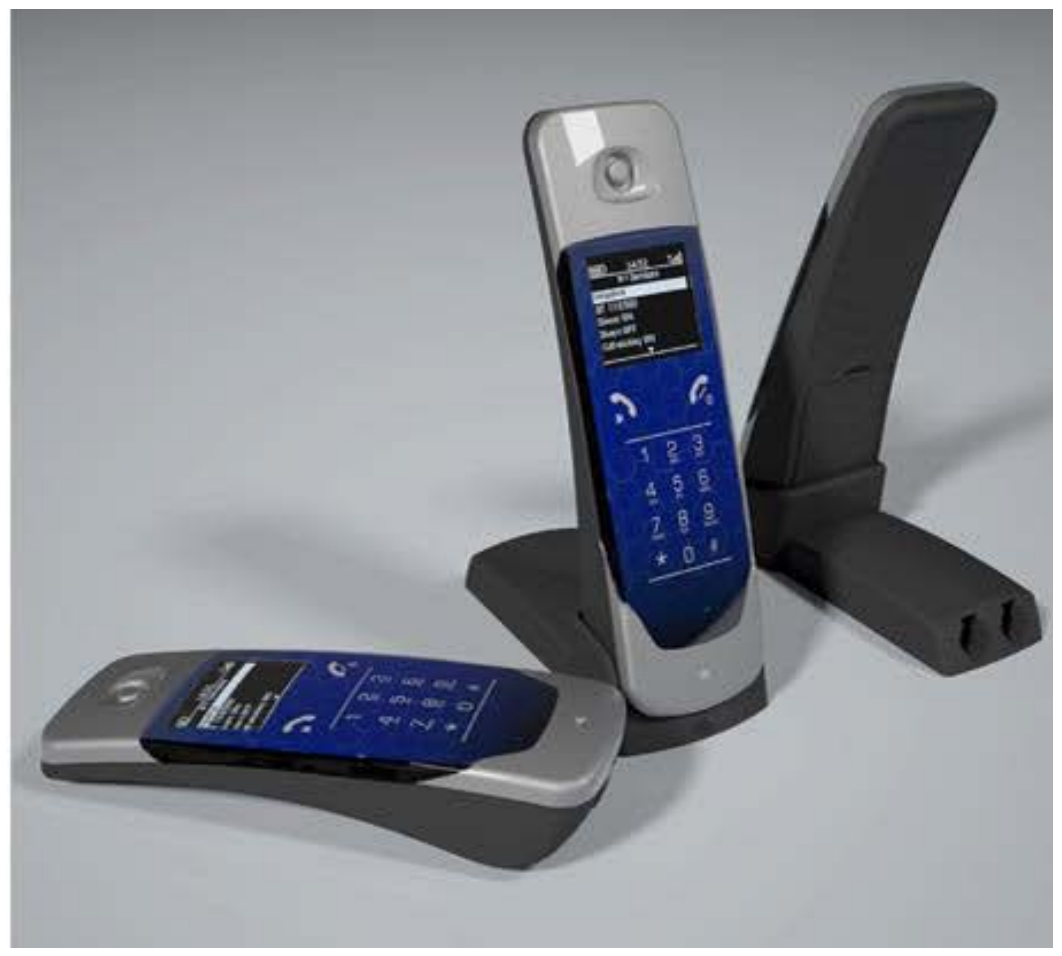

Figure 10 Redesigned handset using capacitive keypad, e-ink display, and surface texturing, original design concept

A solution was developed for clipping together the body halves that involved increasing the length of the three pairs of opposing clips to make them more flexible along with a modification to the battery compartment moulding that prevented the clips from disengaging (Figure 11) as it acted as a buttress (once attached) to prevent these 'longer' clips from moving. The battery compartment therefore also acted as a replacement for screws assisting in end of life disassembly. 


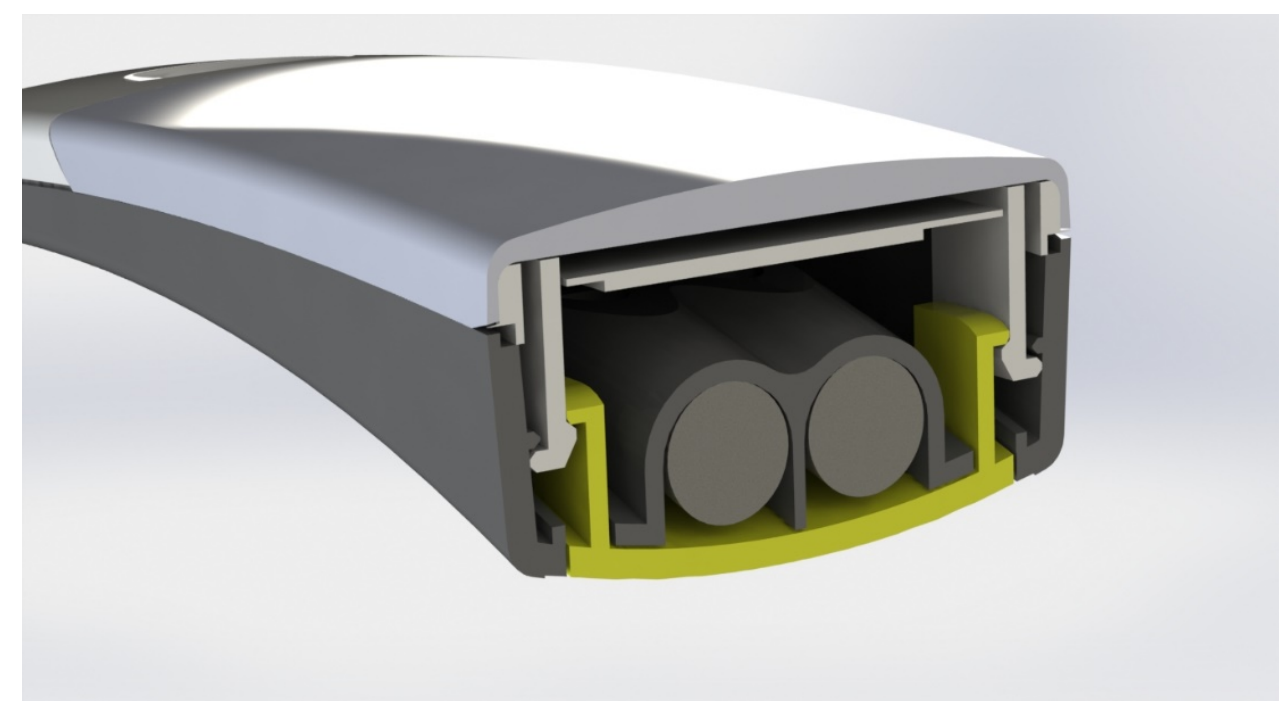

Figure 11 Redesign of clips and modification of battery compartment

\subsubsection{Second prototype}

Prototypes of this second design, including the 'e-ink' display, capacitive keypad, surface texturing, and new clip design, were made in both $A B S$ and $\mathrm{rABS}$ (Figure 12). These were then subject to a variety of tests to compare the performance of the $\mathrm{AABS}$ against the virgin $A B S$.

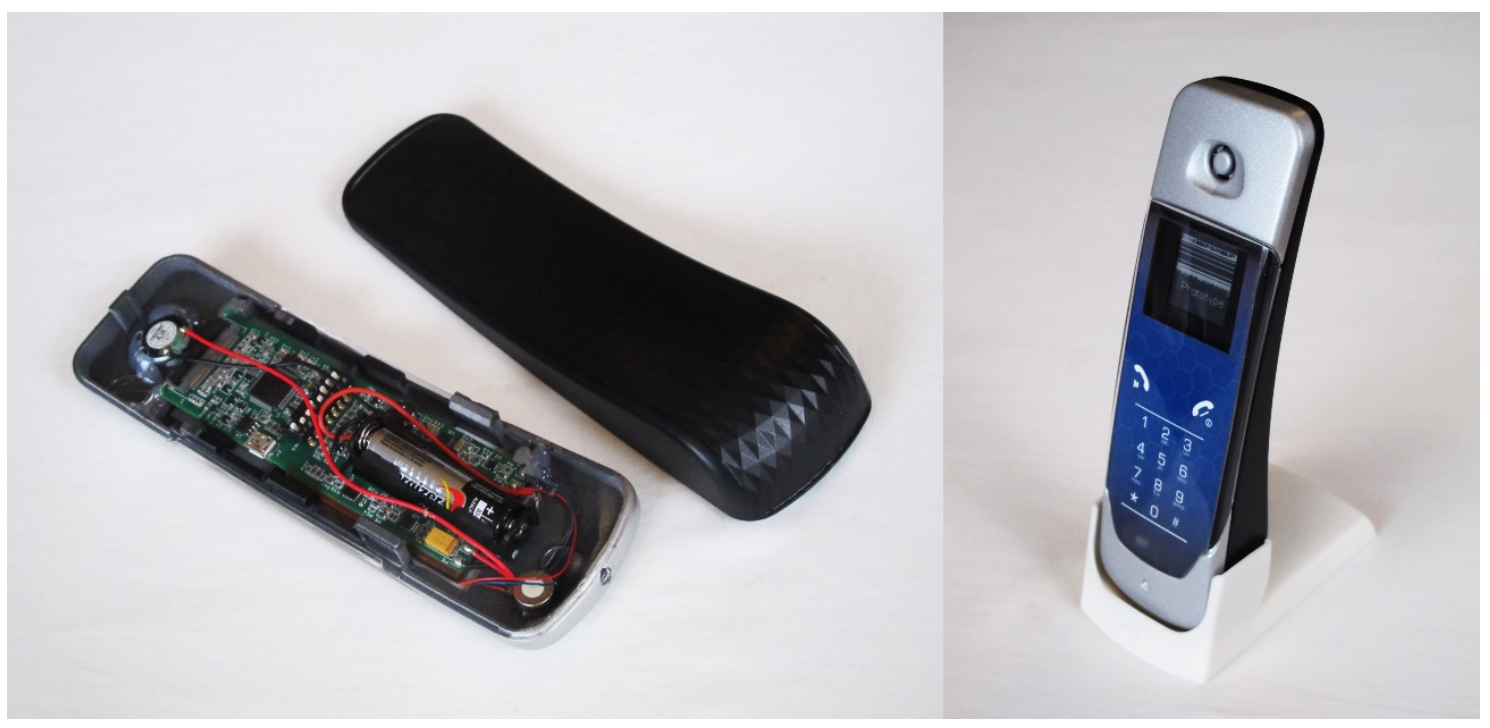

Figure 12 Second prototype

\section{Phase 2 - Method}

A number of test methods were used to compare identical injection moulded samples of $\mathrm{rABS}$ and ABS (Figures 13 and 14) against each other to evaluate their suitability when incorporated into the DECT handset. An injection moulding tool was prepared to allow the production of identical sample handsets in both rABS and ABS. In addition, the LCA was rerun taking into account the differences in design and materials. 


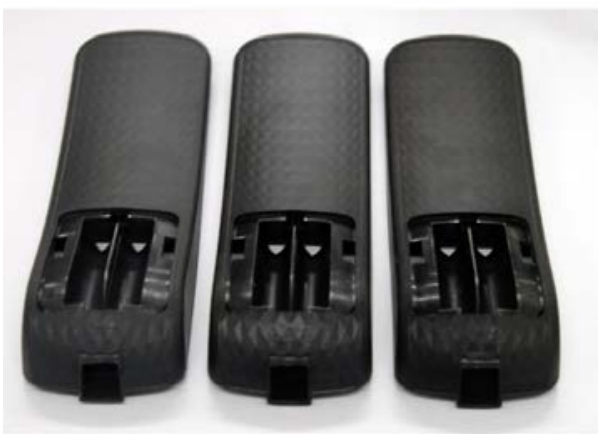

Figure 13 Sample handsets for testing

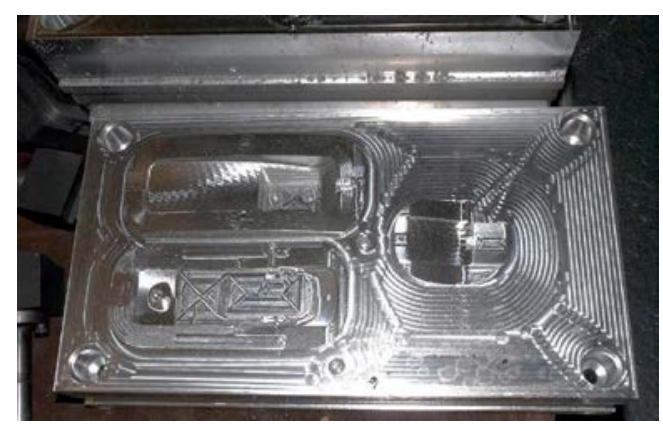

Figure 14 Injection moulding tool

\subsection{Screw Torque Tests}

A calibrated 'dial indicating screwdriver' (Gedore TT500 FH) was used to tighten a M3 thread forming screws into the moulded bosses.

Tests had been undertaken with screw bosses designed to conform to the optimum design for ABS, as specified by the manufacturers of the self-tapping screws. The design performed as expected with the ABS samples but 'stripped' too easily with the rABS samples; further tests were undertaken with rABS samples where the screw boss hole diameter was reduced by $0.2 \mathrm{~mm}$.

The screw was then over-torqued until the plastic boss had stripped; meaning the screw no longer gripped the plastic material. The force at which the boss stripped was recorded for samples of ABS and $\mathrm{rABS}$.

\subsection{Screw Pull-out Tests}

Screw pull-out tests were conducted on the moulded screw bosses using an Instron 3367 Dual Column Testing System to pull an M3 thread forming screw from the mouldings. Custom sample holders were produced in sintered Nylon allowing a screw to be pulled from mouldings which were trimmed down to the area surrounding the bosses.

\subsection{Heat Tests}

Testing was conducted on the handset mouldings to examine the effect of heat on the different polymers, simulating an overheated/faulty battery (for example). The testing was carried out using a 200Watt "AAA battery-sized" cartridge heater. The heater was placed inside an assembled set of DECT handset mouldings in place of a triple-A battery. A sintered Nylon component was produced and used in place of the handset's front lens and a Nylon handset holder was produced to ensure the samples were positioned in the same way throughout the tests. The cartridge heater was connected to a power supply unit to heat up for one hour.

The external temperature of the assembly was monitored periodically throughout the tests using an infrared thermometer and examined for signs of cosmetic and structural damage. 


\subsection{Drop Tests}

Drop tests were carried out on the samples in accordance to S4002 v14 "Dynamic, Environmental \& Ageing Test Requirements for Consumer Devices", test method 'IEC 60068-2-31'; with the handset being dropped from a rig onto its upper and lower faces from a height of 1.5 metres onto a concrete surface. The samples were realistically weighted with batteries in the battery compartment, faux PCBs inside and a nylon lens. The tests were video recorded and the test samples were examined for cosmetic and structural damage. A second round of tests was carried out on the samples where they were dropped repeatedly on the same face 50 times or until the parts failed.

\subsection{Accelerated aged Samples}

Sample mouldings were UV exposed to simulate aging according to ISO 4892-2 (2013) 'Method $B$, Cycle 2 Plastics - Methods of exposure to laboratory light sources: xenon-arc'. The samples were exposed for 2700 hours, being turned $180^{\circ}$ every 250 hours, with the front side receiving 1450 hours and the rear side receiving 1250 ours of exposure. This is the equivalent of 21,600 hours of continuous sunlight. Drop, screw pull-out and tensile tests were carried out on the samples and the results compared to the tests carried out on the non-exposed samples.

\section{$6 \quad$ Phase 2 - Results}

Overall, these tests indicate that there is very little mechanical difference between moulded ABS polymer and moulded $100 \%$ post- consumer recycled ABS polymer.

\subsection{Screw torque test}

The results show, that the rABS did not perform as well as the ABS using the optimum design for $A B S$, as specified by the manufacturers of the self-tapping screws, but when the screw boss hole diameter was reduced by $0.2 \mathrm{~mm}$ the rABS performs as well (if not better) than the ABS (Table 2).

Table 1 Results of screw torque tests

\begin{tabular}{|l|l|l|}
\hline rABS (CNm) & ABS (CNm) & $\begin{array}{l}\text { rABS with modified } \\
\text { screw boss (CNm) }\end{array}$ \\
\hline 78 & 120 & 100 \\
\hline 40 & 85 & 110 \\
\hline 25 & 80 & 80 \\
\hline 52 & 70 & 110 \\
\hline 80 & 80 & 100 \\
\hline 50 & 100 & 100 \\
\hline
\end{tabular}

\subsection{Screw Pull-out Tests}

Although the results are inconsistent for the samples tested the rABS appears to perform as well as the ABS (Table 3). 
Table 2 Results of screw pull-out tests

\begin{tabular}{|l|l|l|l|}
\hline Material & $\begin{array}{l}\text { Maximum Load } \\
\mathbf{( N )}\end{array}$ & Break (Load 0 N) & $\begin{array}{l}\text { Extension at } \\
\text { Break (Load 0 } \\
\mathbf{N}) \mathbf{~ m m}\end{array}$ \\
\hline ABS & 989 & 853 & 7.361 \\
\hline $\begin{array}{l}\text { rABS (modified } \\
\text { boss) }\end{array}$ & 970 & 963 & 5.43 \\
\hline ABS & 628 & 628 & 2.532 \\
\hline $\begin{array}{l}\text { rABS (modified } \\
\text { boss) }\end{array}$ & 1039 & 1034 & 5.697 \\
\hline
\end{tabular}

\subsection{Heat Tests}

There was very little difference between $\mathrm{rABS}$ and $\mathrm{ABS}$ in the temperature at which the moulding showed signs of heat damage visual deformation after one indicated very little actual difference (Table 4).

Table 3 Results of heat test

\begin{tabular}{|l|l|l|l|}
\hline $\begin{array}{l}\text { Temperature at } \\
\text { which the moulding } \\
\text { shows signs of heat } \\
\text { damage externally } \\
\text { (rABS) (degrees } \\
\text { centigrade) }\end{array}$ & $\begin{array}{l}\text { Temperature at } \\
\text { which the moulding } \\
\text { shows signs of heat } \\
\text { damage externally } \\
\text { (ABS) (degrees } \\
\text { centigrade) }\end{array}$ & $\begin{array}{l}\text { Temperature after } \\
\text { 1hr (rABS) (degrees } \\
\text { centigrade) }\end{array}$ & $\begin{array}{l}\text { Temperature after } \\
\text { 1hr (ABS) (degrees } \\
\text { centigrade) }\end{array}$ \\
\hline 80 & 80 & 116 & 107 \\
\hline 88 & 85 & 105 & 114 \\
\hline 82 & 88 & 125 & 101 \\
\hline 84 & 86 & 127 & 104 \\
\hline 82 & 82 & 128 & 102 \\
\hline
\end{tabular}

\subsection{Drop Tests}

Results of the drop tests shown in Figure 15 indicate that the ABS and $\mathrm{rABS}$ performed well, but that the $\mathrm{rABS}$ showed slightly more cosmetic damage. There was no internal clip geometry cracking or breaking in either sample.

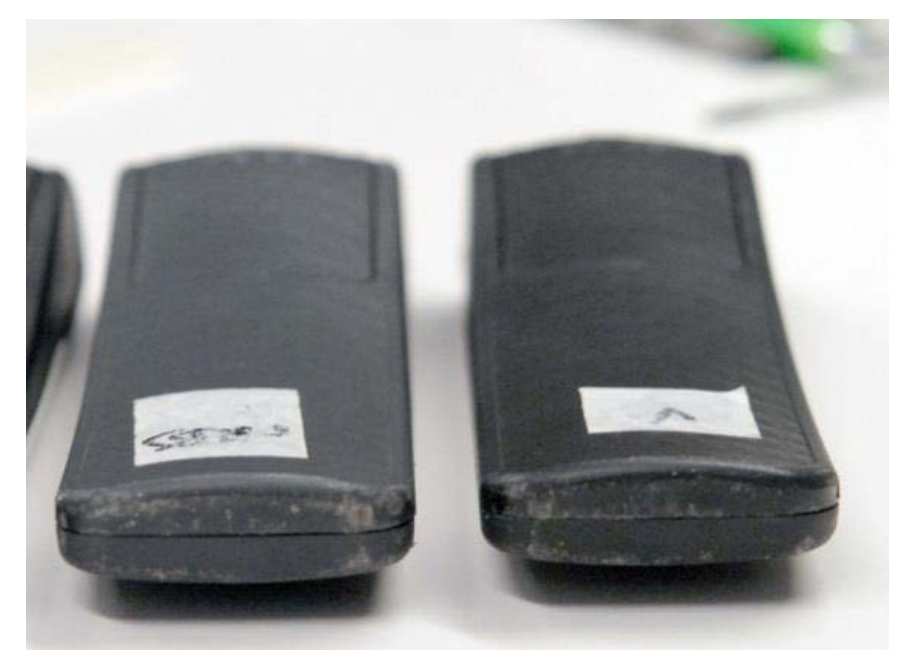

Figure 15 Injection moulded samples - drop test sample examination after 50 drops, rABS on left, ABS on right 


\subsection{Accelerated aged Samples}

The number of samples tested was limited, but the indication is that $\mathrm{rABS}$ out performs the ABS by a significant factor in the tensile test (Table 5) and in the screw pull out (Table 6) (with a non-modified boss for the rABS sample), there is very little difference in performance.

Table 4 UV exposed material sample tensile test results

\begin{tabular}{|l|l|l|l|l|}
\hline & Material & $\begin{array}{l}\text { Maximum Load } \\
\text { (N) }\end{array}$ & Break (Load O N) & $\begin{array}{l}\text { Extension at } \\
\text { Break (Load 0 N) } \\
\text { mm }\end{array}$ \\
\hline 1 & UV exposed ABS & 816 & 816 & 0.758 \\
\hline 2 & $\begin{array}{l}\text { UV exposed } \\
\text { rABS }\end{array}$ & 1743 & 1530 & 2.758 \\
\hline
\end{tabular}

Table 5 UV exposed material sample screw pull out test results

\begin{tabular}{|l|l|l|l|l|}
\hline & Material & $\begin{array}{l}\text { Maximum Load } \\
\text { (N) }\end{array}$ & Break (Load O N) & $\begin{array}{l}\text { Extension at } \\
\text { Break (Load O N) } \\
\text { mm }\end{array}$ \\
\hline 1 & UV exposed ABS & 981 & 845 & 4.443 \\
\hline 2 & $\begin{array}{l}\text { UV exposed } \\
\text { rABS (non- } \\
\text { modified screw } \\
\text { boss) }\end{array}$ & 974 & 956 & 4.582 \\
\hline
\end{tabular}

The UV exposed samples (ABS and $\mathrm{rABS}$ ) passed the drop tests, with no internal clip geometry cracking or breaking after 50 drops. After inspection, there were no noticeable differences between the UV exposed mouldings and the non-exposed mouldings.

\subsection{Life Cycle Analysis}

The results of the LCA for the second prototype show a reduction in material use compared to the original handset (Table 2).

Table 2 Materials list for redesigned handset

\begin{tabular}{|l|l|c|c|c|c|c|c|}
\hline & & \multicolumn{1}{|c|}{$\begin{array}{l}\text { Recycled } \\
\text { content* } \\
\text { (\%) }\end{array}$} & $\begin{array}{l}\text { Part } \\
\text { mass } \\
\text { (kg) }\end{array}$ & Qty. & $\begin{array}{l}\text { Total mass } \\
\text { processed** } \\
\text { (kg) }\end{array}$ & $\begin{array}{c}\text { Energy } \\
\text { (MJ) }\end{array}$ & $\%$ \\
\hline $\begin{array}{l}\text { Packaging (outer } \\
\text { box) }\end{array}$ & Cardboard & $50.00 \%$ & 0.084 & 1 & 0.088 & 2.8 & 2 \\
\hline $\begin{array}{l}\text { Packaging inner } \\
\text { box }\end{array}$ & $\begin{array}{l}\text { Paper (cellulose } \\
\text { based) }\end{array}$ & $75.00 \%$ & 0.14 & 1 & 0.15 & 4.4 & 3.2 \\
\hline $\begin{array}{l}\text { Handset upper } \\
\text { casing }\end{array}$ & $\begin{array}{l}\text { rABS (medium- } \\
\text { impact, injection } \\
\text { molding) }\end{array}$ & $\begin{array}{l}100 \% \\
\text { recycled }\end{array}$ & 0.021 & 2 & 0.042 & 1.68 & 2.9 \\
\hline $\begin{array}{l}\text { Hanndset lower } \\
\text { casing }\end{array}$ & $\begin{array}{l}\text { rABS (medium- } \\
\text { impact, injection } \\
\text { molding) }\end{array}$ & $\begin{array}{l}100 \% \\
\text { recycled }\end{array}$ & 0.026 & 2 & 0.052 & 2.08 & 3.1 \\
\hline $\begin{array}{l}\text { Handset battery } \\
\text { cover }\end{array}$ & $\begin{array}{l}\text { rABS (medium- } \\
\text { impact, injection } \\
\text { molding) }\end{array}$ & $\begin{array}{l}100 \% \\
\text { recycled }\end{array}$ & 0.004 & 2 & 0.008 & 0.32 & 12.1 \\
\hline
\end{tabular}




\begin{tabular}{|c|c|c|c|c|c|c|c|}
\hline Handset PCB & $\begin{array}{l}\text { Printed circuit } \\
\text { board assembly }\end{array}$ & $\begin{array}{l}\text { Virgin } \\
(0 \%)\end{array}$ & 0.018 & 2 & 0.035 & 4.6 & 3.4 \\
\hline $\begin{array}{l}\text { Handset LCD } \\
\text { Diffuser }\end{array}$ & $\begin{array}{l}\text { Toughened } \\
\text { acryllic }\end{array}$ & $\begin{array}{l}\text { Virgin } \\
(0 \%)\end{array}$ & 0.017 & 2 & 0.034 & 0.75 & \\
\hline Handset Speaker & $\begin{array}{l}\text { Carbon steel, } \\
\text { AISI 1010, } \\
\text { annealed }\end{array}$ & Typical \% & 0.0035 & 2 & 0.007 & 0.13 & 0.1 \\
\hline $\begin{array}{l}\text { Main base lower } \\
\text { casing }\end{array}$ & $\begin{array}{l}\text { rABS (medium- } \\
\text { impact, injection } \\
\text { molding) }\end{array}$ & $\begin{array}{l}100 \% \\
\text { recycled }\end{array}$ & 0.048 & 1 & 0.048 & 0.91 & 3.3 \\
\hline $\begin{array}{l}\text { Main base upper } \\
\text { casing }\end{array}$ & $\begin{array}{l}\text { rABS (medium- } \\
\text { impact, injection } \\
\text { molding) }\end{array}$ & $\begin{array}{l}100 \% \\
\text { recycled }\end{array}$ & 0.028 & 1 & 0.028 & 0.53 & 1.9 \\
\hline $\begin{array}{l}\text { Main base phone } \\
\text { 'cradle' }\end{array}$ & $\begin{array}{l}\text { rABS (medium- } \\
\text { impact, injection } \\
\text { molding) }\end{array}$ & $\begin{array}{l}100 \% \\
\text { recycled }\end{array}$ & 0.0048 & 1 & 0.0048 & 0.09 & 0.3 \\
\hline $\begin{array}{l}\text { Main base upper } \\
\text { circuit board }\end{array}$ & $\begin{array}{l}\text { Printed circuit } \\
\text { board assembly }\end{array}$ & $\begin{array}{l}\text { Virgin } \\
(0 \%)\end{array}$ & 0.013 & 1 & 0.013 & 1.7 & 1.3 \\
\hline $\begin{array}{l}\text { Main base lower } \\
\text { circuit board }\end{array}$ & $\begin{array}{l}\text { Printed circuit } \\
\text { board assembly }\end{array}$ & $\begin{array}{l}\text { Virgin } \\
(0 \%)\end{array}$ & 0.0049 & 1 & 0.0049 & 0.64 & 0.5 \\
\hline Main base feet & $\begin{array}{l}\text { Ethylene } \\
\text { propylene } \\
\text { (diene) } \\
\text { (EPDM/EPM, } \\
\text { unreinforced) }\end{array}$ & $\begin{array}{l}\text { Virgin } \\
(0 \%)\end{array}$ & 0.0007 & 1 & 0.0007 & 0.066 & 0 \\
\hline $\begin{array}{l}\text { Screws and metal } \\
\text { contatcs }\end{array}$ & $\begin{array}{l}\text { Carbon steel, } \\
\text { AISI 1010, } \\
\text { annealed }\end{array}$ & Typical \% & 0.0029 & 1 & 0.0029 & 0.053 & 0 \\
\hline Keypad frame & $\begin{array}{l}\text { ABS (medium- } \\
\text { impact, injection } \\
\text { molding) }\end{array}$ & $\begin{array}{l}\text { Virgin } \\
(0 \%)\end{array}$ & 0.0039 & 1 & 0.0039 & 0.37 & 0.3 \\
\hline Keypad buttons & $\begin{array}{l}\text { ABS (medium- } \\
\text { impact, injection } \\
\text { molding) }\end{array}$ & $\begin{array}{l}\text { Virgin } \\
(0 \%)\end{array}$ & 0.0049 & 1 & 0.0049 & 0.47 & 0.3 \\
\hline Keypad 'pad' & $\begin{array}{l}\text { Silicone (VMQ, } \\
\text { heat cured, low } \\
\text { hardness) }\end{array}$ & $\begin{array}{l}\text { Virgin } \\
(0 \%)\end{array}$ & 0.0064 & 1 & 0.0064 & 0.89 & 0.6 \\
\hline $\begin{array}{l}\text { Slave base upper } \\
\text { casing }\end{array}$ & $\begin{array}{l}\text { rABS (medium- } \\
\text { impact, injection } \\
\text { molding) }\end{array}$ & $\begin{array}{l}100 \% \\
\text { recycled }\end{array}$ & 0.022 & 1 & 0.022 & 0.418 & 1.5 \\
\hline $\begin{array}{l}\text { Slave base lower } \\
\text { casing }\end{array}$ & $\begin{array}{l}\text { rABS (medium- } \\
\text { impact, injection } \\
\text { molding) }\end{array}$ & $\begin{array}{l}100 \% \\
\text { recycled }\end{array}$ & 0.033 & 1 & 0.033 & 0.627 & 2.3 \\
\hline $\begin{array}{l}\text { Slave base phone } \\
\text { 'cradle' }\end{array}$ & $\begin{array}{l}\text { rABS (medium- } \\
\text { impact, injection } \\
\text { molding) }\end{array}$ & $\begin{array}{l}100 \% \\
\text { recycled }\end{array}$ & 0.0048 & 1 & 0.0048 & 0.0912 & 0.3 \\
\hline $\begin{array}{l}\text { Slave base circuit } \\
\text { board }\end{array}$ & $\begin{array}{l}\text { Printed circuit } \\
\text { board assembly }\end{array}$ & $\begin{array}{l}\text { Virgin } \\
(0 \%)\end{array}$ & 0.0016 & 1 & 0.0016 & 0.21 & 0.2 \\
\hline Slave base wires & Cable & $\begin{array}{l}\text { Virgin } \\
(0 \%)\end{array}$ & 0.0033 & 1 & 0.0033 & 0.3 & 0.2 \\
\hline $\begin{array}{l}\text { Slave base weight } \\
\text { connectors and } \\
\text { screws }\end{array}$ & $\begin{array}{l}\text { Carbon steel, } \\
\text { AISI 1010, } \\
\text { annealed }\end{array}$ & Typical \% & 0.033 & 1 & 0.033 & 0.6 & 0.4 \\
\hline Slave base feet & $\begin{array}{l}\text { Ethylene } \\
\text { propylene } \\
\text { (diene) } \\
\text { (EPDM/EPM, } \\
\text { unreinforced) } \\
\end{array}$ & $\begin{array}{l}\text { Virgin } \\
(0 \%)\end{array}$ & 0.0007 & 1 & 0.0007 & 0.066 & 0 \\
\hline Power supply & $\begin{array}{c}\text { Power supply } \\
\text { unit }\end{array}$ & $\begin{array}{l}\text { Virgin } \\
(0 \%)\end{array}$ & 0.085 & 2 & 0.17 & 77 & 56.3 \\
\hline Total & & & & 37 & 0.95 & $1.02 E+02$ & 100 \\
\hline
\end{tabular}


There may also be an increase in the end of life potential and a potential reduction in energy use over the lifetime of the product (Figure 16). In addition, there was a significant reduction in number of components and weight, and a reduction in production costs of approximated $£ 1.00$ per handset.

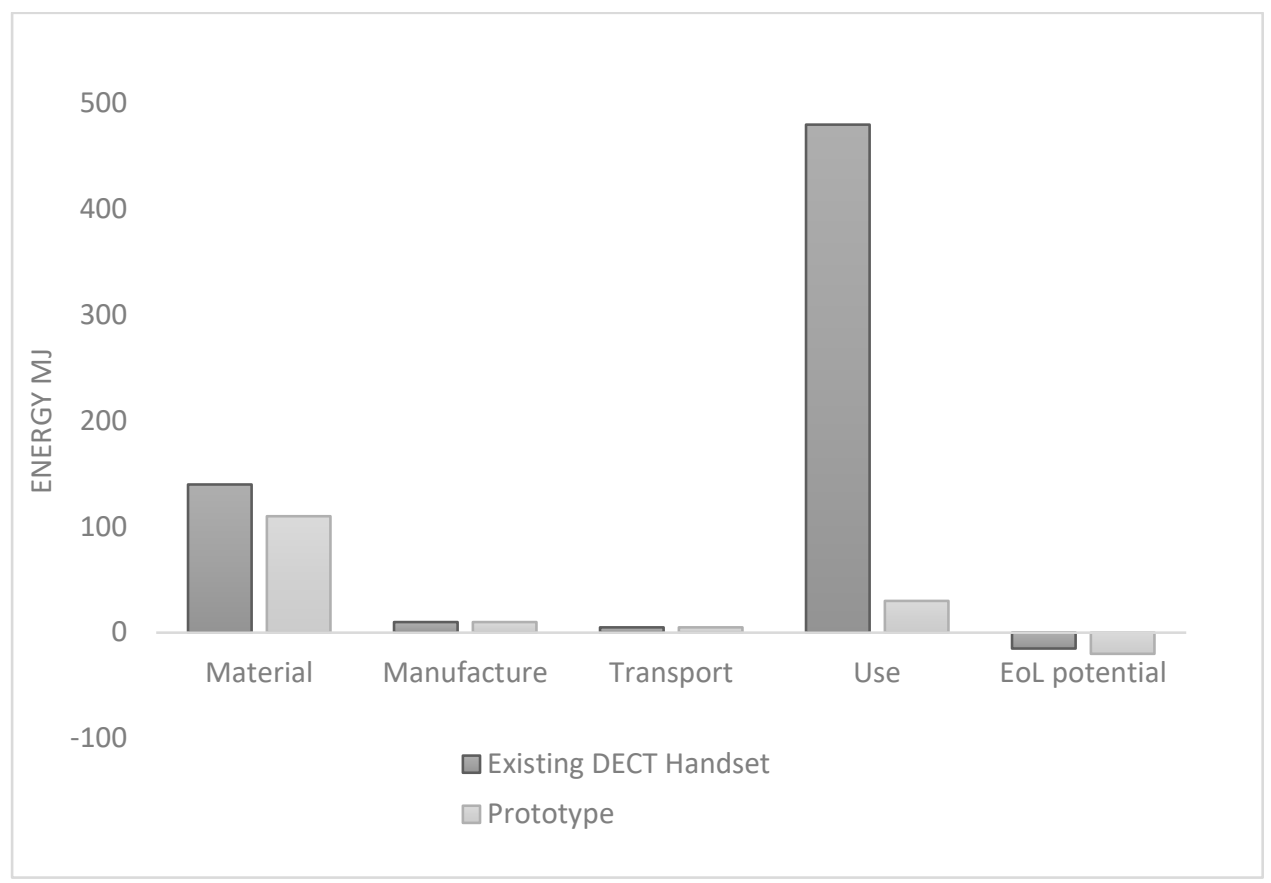

Figure 16 Comparison of initial estimates for energy use between original handset and prototype two assuming 5-year life

\section{Discussion}

This study illustrates the potential for designers to expand the ambition of manufacturers to improve the sustainability of their products. What started as an evaluation of the strength, colour and texturing characteristics of $100 \%$ rABS, in order to identify any constraints imposed by the properties of the material, and to develop insights on how to address these limits, evolved into the full design development of a concept DECT handset driven by the need to be more circular in its conception.

The authors were originally commissioned by TP to assess the suitability of $\mathrm{rABS}$ as a replacement for virgin $A B S$ in the hopes of improving the circular economy credentials of their products. However, the study was widened to include an LCA of the DECT phone which suggested that there was potential for improvement in other areas as well. Working progressively with TP the authors were able to encourage the company to consider a more thorough redesign of the phone to allow it to fit better the needs of the circular economy. In addition to using rABS the new design substituted a capacitive touch keypad and e-ink display reducing both the number and weight of components, and the cost to manufacture the handset compared to the original. The LCA of the final design indicated substantial reductions in energy related to the handset's material use and operational life (and associated carbon reductions). In addition, the handset had significantly improved end of life credentials, proving easy to disassemble and with the potential for re-using a high proportion component parts and materials.

The study demonstrated that $100 \%$ recycled $A B S$ has similar properties to virgin $A B S$ and can be substituted for virgin $A B S$ as long as the product design allows for the slightly stiffer nature of the rABS and addresses issues of surface finish. By careful design decisions it was possible to produce an 
rABS handset which was as robust as one made of virgin ABS. Other than the more abrupt failure point of the $\mathrm{rABS}$ there were no significant differences in the performance of the two materials. This suggests that the recycled material could be used widely in this type of product.

However, issues with using recycled materials have been identified in the literature, in terms of consumer acceptance as well as suitability of the material. Designers interviewed in a study by Singh and Ordonez (2016) found issues with the quality of some products designed using recycled materials and the reaction of TP to the heat-shrink on the first prototype demonstrates the importance of consumer preference. It is important that designers overcome any prejudice about recycled material by attractive product design. Products made from recycled materials have to compete in existing markets with products made from virgin materials, and recycled materials are not necessarily seen to be enough to make a product desirable (Singh and Ordonez 2016).

The impact of these investigations to date is evidenced by TP's key suppliers adopting the use of rABS within new designs of their own products (in addition to new products for TP) and therefore incorporating and building on the key learnings from this research.

\section{Conclusion}

This study assessed a representative small electronic product and has demonstrated that many of the issues associated with the environmental impact of the product can be relatively easily addressed at the design stage by applying a number of simple practical design rules. These rules relate to material choices and manufacturing practices as well as in-use impacts and the eventual end-of-life of products.

The study also evaluated the feasibility of the use of $100 \%$ recycled ABS in the manufacture of a small electronic products through primary research on colour, surface finish and strength using test plaques and strips. Using a DECT handset as a representative example of such products Finite Element Analysis and further materials testing showed that careful design choices would allow $100 \%$ rABS to be substituted for virgin ABS in the manufacture of the handset.

The continual development of new technologies affords a number of opportunities to move towards a more circular economy. The use of these technologies can reduce the impact of products, ensure materials are easier to recover and ultimately reduce the overall resource burden required to deliver the functions and services provided by the products we buy, use and dispose of.

Product design is a key part of the circular economy and if undertaken in the correct manner it can contribute considerably to the overall reduction of resource use in modern society. This study demonstrates that product designers are well positioned to increase the ambition of manufacturers by demonstrating both the feasibility and cost-effectiveness of embracing more sustainable materials and processes. 


\section{References}

Bakker, C., Wang, F., Huisman, J. and den Hollander, M., 2014. Products that go round: exploring product life extension through design. Journal of Cleaner Production, 69, pp.10-16.

doi.org/10.1016/j.jclepro.2014.01.028

Bocken, N.M., de Pauw, I., Bakker, C. and van der Grinten, B., 2016. Product design and business model strategies for a circular economy. Journal of Industrial and Production Engineering, 33(5), pp.308-320., doi.org/10.1080/21681015.2016.1172124

Chang, D., Lee, C.K.M. and Chen, C.H., 2014. Review of life cycle assessment towards sustainable product development. Journal of cleaner production, 83, pp.48-60.

doi.org/10.1016/j.jclepro.2014.07.050

Cooper, T., 2005. Slower consumption reflections on product life spans and the "throwaway society". Journal of Industrial Ecology, 9(1-2), pp.51-67. doi.org/10.1162/1088198054084671

De los Rios, I.C. and Charnley, F.J., 2017. Skills and capabilities for a sustainable and circular economy: The changing role of design. Journal of Cleaner Production, 160, pp.109-

122.doi.org/10.1016/j.jclepro.2016.10.130

EMF (Ellen MacArthur Foundation), 2012. Towards the Circular Economy Vol. 1: an economic and business rationale for an accelerated transition.

https://www.ellenmacarthurfoundation.org/publications/towards-the-circular-economy-vol-1-aneconomic-and-business-rationale-for-an-accelerated-transition (accessed 27th October 2018)

EMF (Ellen MacArthur Foundation), 2013. Towards the circular economy Vol. 2: opportunities for the consumer goods sector. https://www.ellenmacarthurfoundation.org/publications/towards-thecircular-economy-vol-2-opportunities-for-the-consumer-goods-sector (accessed 27 October 2018)

Granta Design. Cambridge Engineering Selector http://www.grantadesign.com/products/ces/ (accessed 27 October 2018)

Go, T.F., Wahab, D.A. and Hishamuddin, H., 2015. Multiple generation life-cycles for product sustainability: the way forward. Journal of Cleaner Production, 95, pp.16-29. doi.org/10.1016/j.jclepro.2015.02.065

Maxwell, D. and Van der Vorst, R., 2003. Developing sustainable products and services. Journal of Cleaner Production, 11(8), pp.883-895. doi.org/10.1016/S0959-6526(02)00164-6

Ramani, K., Ramanujan, D., Bernstein, W.Z., Zhao, F., Sutherland, J., Handwerker, C., Choi, J.K., Kim, H. and Thurston, D., 2010. Integrated sustainable life cycle design: a review. Journal of Mechanical Design, 132(9), p.091004.

Rosen, M.A. and Kishawy, H.A., 2012. Sustainable manufacturing and design: Concepts, practices and needs. Sustainability, 4(2), pp.154-174. doi:10.3390/su4020154

Scaffaro, R., Botta, L. and Di Benedetto, G., 2012. Physical properties of virgin-recycled ABS blends: Effect of post-consumer content and of reprocessing cycles. European Polymer Journal, 48(3), pp.637-648. doi.org/10.1016/j.eurpolymj.2011.12.018 
Singh, J. and Ordoñez, I., 2016. Resource recovery from post-consumer waste: important lessons for the upcoming circular economy. Journal of Cleaner Production, 134, pp.342-353.

doi.org/10.1016/j.jclepro.2015.12.020

Souza, A.M.C. and Cucchiara, M.C., 2018, July. Mechanical properties of virgin ABS/post-consumer ABS blends. In AIP Conference Proceedings (Vol. 1981, No. 1, p. 020179). AIP Publishing.

doi.org/10.1063/1.5046041

Vlugter, J., 2017. Scaling recycled plastics across industries, MSc Report, Delft

University of technology : https://www.ellenmacarthurfoundation.org/assets/downloads/ce100/

Scaling-Recycled-Plastics-across-Industries.pdf (accessed 27 October 2018)

Yung, W.K., Chan, H.K., So, J.H., Wong, D.W., Choi, A.C. and Yue, T.M., 2011. A life-cycle assessment for eco-redesign of a consumer electronic product. Journal of Engineering Design, 22(2), pp.69-85. doi.org/10.1080/09544820902916597 